Uludag Univ. J. Fac. Vet. Med.

32 (2013), 2: 25-29

\title{
Damızlık Yumurtacı Tavuk Rasyonlarına Bitkisel Kaynaklı 1.25-dihidroksikolekalsiferol Katılmasının Yumurta Kabuk Kalitesi ve Kuluçka Sonuçlarına Etkisi
}

\author{
Gülay DENIZ ${ }^{1}$ Arda KOVANLIKAYA² Ece ERTEK ${ }^{3}$
}

Geliş Tarihi: 05.03.2014

Kabul Tarihi: 30.04 .2014

\begin{abstract}
Özet: $\mathrm{Bu}$ araştırmanın amacı; damızlık yumurtacı tavuk rasyonlarına (Lohmann LB) bitkisel kaynaklı 1.25dihidroksikolekalsiferol $\left(1.25(\mathrm{OH})_{2} \mathrm{D}_{3}\right)$ katılmasının, yumurta kabuk kalitesi ve çıkım sonuçları üzerindeki etkilerini belirlemekti. Araştırma; 38 haftalık yaşta 20000 damızlık yumurtacı (Lohmann LB) tavuğun bakıldığı Hastavuk A.Ş.'ye ait damızlık kümesinde yürütüldü. Araştırmada kullanılan rasyonlar yine Hastavuk A.Ş.'ye ait yem fabrikasında toz formda hazırlandı. Araştırma süresince (38-48. haftalar); kontrol grubundaki hayvanlar standart damızlık yumurtacı tavuk rasyonu ile beslenirken, deneme grubunun rasyonuna kontrol grubundan farklı olarak 10 ppm dozda bitkisel kaynakl1 $1.25(\mathrm{OH})_{2} \mathrm{D}_{3}$ katıldı. $1.25(\mathrm{OH})_{2} \mathrm{D}_{3}$ katkılı rasyonu tüketen deneme grubunun yumurta kabuk kalınlığında $40(\mathrm{P}<0.05)$ ve 48 . $(\mathrm{P}<0.01)$ haftalarda, yumurta kabuk kırılma direncinde ise 42. haftada $(\mathrm{P}<0.05)$ istatistik düzeyde bir iyileşme saptandı. Ancak araștırma süresince yapılan ölçümler total olarak değerlendirildiğinde (38-48. haftalar), kontrol ve deneme grubunun kabuk kalitesi ve kuluçka sonuçları arasında oluşan farklılıkların istatistik açıdan önem taşımadığı tespit edildi. Sonuç olarak; Vitanin D'nin aktif formu olan $1.25(\mathrm{OH})_{2} \mathrm{D}_{3}$ 'ün, vitamin $\mathrm{D}$ metabolizmasında aksaklıkların yaşandığı yaşlı hayvanların rasyonlarına katılması durumunda etkili olabileceği kanısına varıldı.
\end{abstract}

Anahtar Kelimeler: Damızlık yumurtacı tavuk, 1.25-dihidroksikolekalsiferol, kabuk kalitesi, kuluçka sonuçları.

\section{Effect of Herbal 1.25-dihydroxycholecalciferol Supplementation into Layer Breeder Diets on Eggshell Quality and Hatching Results}

\begin{abstract}
The aim of this study was to determine effects of herbal 1.25-dihydroxycholecalciferol $\left(1.25(\mathrm{OH})_{2} \mathrm{D}_{3}\right)$ supplementation on the eggshell quality and hatching results in layer breeders. The experiment was performed at breeding hen house containing 20000 layer breeders (38 weeks old) which belongs to joint-stock company Hastavuk. The diets used in experiment also were prepared at the same company. During experiment $\left(38^{\text {th }}-48^{\text {th }}\right.$ weeks), layer breeders in control group were fed with standart layer breeder diets, while treatment group were fed diet containing $10 \mathrm{ppm}$ of herbal $1.25(\mathrm{OH})_{2} \mathrm{D}_{3}$ differently from control group. A significant improvement was determined in eggshell quality at $40^{\text {th }}(\mathrm{P}<0.05)$ and $48^{\text {th }}(\mathrm{P}<0.01)$ weeks and in eggshell breaking strength at $42^{\text {nd }}(\mathrm{P}<0.05)$ week in treatment group supplemented fed with $1.25(\mathrm{OH})_{2} \mathrm{D}_{3}$. However, when the measurements performed during experiment were evaluated totally $\left(38^{\text {th }}-48^{\text {th }}\right.$ weeks), there was no significiant difference between control and treatment group in eggshell quality and hatching results. It was concluded that the supplementation of $1.25(\mathrm{OH})_{2} \mathrm{D}_{3}$ (active form of vitamin $\mathrm{D}$ ) to the diets of old layer breeders who has an irregular Vitamin D metabolism may be effective.
\end{abstract}

Key Words: Layer Breeder, 1.25-dihydroxycholecalciferol, eggshell quality, hatcing results.

1 U.Ü. Veteriner Fakültesi, Hayvan Besleme ve Beslenme Hastalıkları Anabilim Dalı, Bursa. denizg@uludag.edu.tr

2 Hastavuk A.Ş., Görükle, Nilüfer, Bursa.

3 Bursa Yem A.Ş., Hürriyet, Osmangazi, Bursa. 


\section{Giriş}

Damızlık olarak yetiştirilen kanatlı hayvanlarda gerek genetik gerekse çevresel pek çok faktör kuluçka sonuçları üzerinde etkili olmaktadır. Kuluçka sonuçlarını etkileyen çevresel faktörlerin başında; damızlık hayvanların yaşı, canlı ağırlığı, yumurtanın iç ve dış kalite özellikleri ile depolanma süresi, mevsim, hastalıklar ve beslenme gelmektedir ${ }^{12}$. Damızlık tavukların yetersiz beslenmesi sonucu, yumurtada besin maddesi yönünden oluşan eksiklikler embriyo gelişiminde olumsuz etkilere yol açmaktadır ${ }^{8}$. Ayrıca, yumurtanın dış kalite özelliklerinden biri olan yumurta kabuk kalitesi, kuluçka sonuçlarını etkileyen en önemli faktörler arasında yer almaktadır ${ }^{13}$. Damızlık tavukların vitamin D ihtiyaçlarının tam olarak karşılanmaması, yumurta kabuk kalitesinde bozulmaya yol açarak kuluçka sonuçlarını olumsuz yönde etkilemektedir $^{17}$. Kabuk kalitesinin yanı sira embriyonun kalsiyum (Ca) metabolizmasında da önemli görevleri olan vitamin D'nin yumurtada yetersiz düzeyde olması, geç dönem embriyo ölümlerine yol açarak kuluçka randımanının azalmasına neden olmaktadır ${ }^{9,10}$. Pratikte damızlık tavukların vitamin D ihtiyaçları rasyona ilave edilen vitamin premiksleri içerisinde yer alan kolekalsiferol $\left(\mathrm{D}_{3}\right)$ yoluyla karşılanmaktadır. Ancak kanatlı vücudunda biyolojik olarak aktif olmayan vitamin $\mathrm{D}_{3}$ 'ün etkinliğini gösterebilmesi için çeşitli enzimlerin etkisiyle önce tavuğun karaciğerinde 25-hidroksikolekalsiferol'e, daha sonra böbreklerinde 1.25dihidroksikolekalsiferol'e $\left(1.25(\mathrm{OH})_{2} \mathrm{D}_{3}\right)$ çevrilmesi gerekmektedir ${ }^{5}$. Vitamin $\mathrm{D}_{3}$ 'ün aktif formu olan $1.25(\mathrm{OH})_{2} \mathrm{D}_{3}$; Ca ve fosfor $(\mathrm{P}) \mathrm{me}-$ tabolizmasının regülasyonunda görev almakta$\mathrm{d}_{1} \mathrm{r}^{4}$. Bu regülasyon; Ca ve P'un barsaklardan emilimini, kemiklerde depolanmasını ve böbreklerden atılımını kapsamaktadır ${ }^{4,10}$.

Kanatlı hayvanlarda $1.25(\mathrm{OH})_{2} \mathrm{D}_{3}$ 'ün sentetik formunun kullanılması, rasyona yüksek maliyet getirmesinden dolayı önerilmemektedir. Fakat bazı bitkiler özellikle de Solanum glaucophyllum adlı bir bitki $1.25(\mathrm{OH})_{2} \mathrm{D}_{3}{ }^{\prime}$ ü doğal olarak içermektedir ${ }^{3}$. Güney Amerika'nın 1lıman bölgelerinde yetişen bu bitki toksik olarak kabul edilmekte ve bu bölgelerde otlayan hayvanlarda aşırı tüketimi sonucu vitamin D toksikasyonunda şekillenen hiperkalsemi ve hiperfosfatami durumlarıyla karşılaşılmaktadır. Solanum glaucophyllum'un $1.25(\mathrm{OH})_{2} \mathrm{D}_{3}{ }_{3}^{\prime} \ddot{\mathrm{u}}$ doğal olarak içermesinden dolayı uzun yıllardır hayvan besleme alanında kullanılması yönünde tavsiyeler yapılmış ancak bu bitkiden standardize edilmiş bir ürün son yıllarda üretilebilmiştir.

$\mathrm{Bu}$ araştırma damızlık yumurtacı tavuk rasyonlarına bitkisel (Solanum glaucophyllum) kaynaklı $1.25(\mathrm{OH})_{2} \mathrm{D}_{3}$ katılmasinın; yumurta kabuk kalitesi ve çıkım sonuçları üzerindeki etkilerini belirlemek amacıyla yapılmıştır.

\section{Materyal ve Metot}

$\mathrm{Bu}$ araştırma; 38 haftalık yaşta 20000 damızlık yumurtacı (Lohmann LB) tavuğun bakıldığı Hastavuk A.Ş.'ye ait damızlık kümesinde yürütülmüştür. Damızlık kümesinin birbirinden bağımsız sağlı sollu iki ayrı bölmeden oluşması; bölmelerden birinin kontrol, diğerinin ise deneme grubu olarak değerlendirilmesine olanak tanımıştır.

Araştırmada kullanılan rasyonlar Hastavuk A.Ş.'ye ait Bursa merkezde bulunan yem fabrikasında toz formda hazırlanmıştır. Araştırma süresince; kontrol grubundaki hayvanlar standart damızlı yumurtacı tavuk rasyonu ile beslenirken, deneme grubundaki hayvanların rasyonuna $10 \mathrm{ppm}$ dozda Solanum glaucophyllum kaynakl1 1.25(OH) ${ }_{2} \mathrm{D}_{3}$ (PAN-HVD; Herbonis AG, Basel, Switzerland) katılmıştır. Araştırmada kullanılan damızlık yumurtacı tavuk rasyonunun ham madde bileşimi ve besin madde içeriği Tablo 1'de gösterilmiştir.

Araștırma süresince; gerek kontrol gerekse deneme grubundan elde edilen yumurtalardan kırık-çatlak olanlar günlük olarak kayıt altına alınmıştır. Araştırmanın başlangıcı olan 38. hafta ile $40,42,44$ ve 48 . haftalarda grupların her birinden tesadüfi örnekleme yöntemi ile 120 'şer adet yumurta numunesi alınmıştır. Alınan yumurta numuneleri; yumurta ağırlığı, yumurta kabuk kalınlığı ve yumurta kabuk kırılma direnci bakımından değerlendirilmek üzere Uludağ Üniversitesi Veteriner Fakültesi Hayvan Besleme ve Beslenme Hastalıkları Anabilim Dalı Laboratuvar'ına getirilerek oda sıcaklığında 24 saat süreyle depolanmıştır. Kontrol ve deneme grubunun yumurta ağırlıkları, yumurtaların $0.01 \mathrm{~g}$ hassasiyette Oertling marka hassas terazide tek tek tartılması suretiyle belirlenmiştir. Yumurta kabuk kalınlığının ölçülmesinde Egg Shell Thickness Gauge (ESTG-1, ORKA Food Technology Ltd., Ramat Hasharon, Israel) isimli cihaz kullanılmıştır. Her bir yumurtanın küt, sivri ve orta bölümünden yapılan toplam 3 ölçümün ortalaması alınmak suretiyle kontrol ve deneme grubuna ait yumurtaların kabuk kalın- 
11kları saptanmıștır. Yumurta kabuk kırılma direnci ise kuvvet ölçme test cihazı (Imada ${ }^{\circledR}$, Newton) kullanılarak belirlenmiştir ${ }^{1}$. Araştırma süresince yumurta kabuk kalitesinin belirlenmesi amaciyla kontrol ve deneneme grubunun her birinden 600 yumurta olmak üzere toplam 1200 yumurta değerlendirilmeye alınmıştır.

Toplam 2.5 ay olan araştırma süresince; kontrol ve deneme grubundan elde edilen yumurtalar, Hastavuk A.Ş.'ye ait kuluçkahanenin rutin işleyiş düzenine uygun olarak 16 parti halinde kuluçkaya konulmuş ve 16 çıkım sonucu elde edilmiştir. Çıkım sonuçları yine Hastavuk A.Ş.'nin rutin kayıt sistemi gereğince kayıt altına alınmıştır. $\mathrm{Bu}$ araştırmada bitkisel kaynaklı $1.25(\mathrm{OH})_{2} \mathrm{D}_{3}$ 'ün damızlık yumurtacı tavukların kuluçka sonuçlarına etkisini belirlemek amaciyla; kontrol ve deneme grubuna ait dölsüz yumurta, çıkım, sskarta civciv ve embriyo ölüm oranları değerlendirmeye alınmıştır. Embriyo ölümleri; erken (0-6 gün), orta (7-17 gün) ve geç (18-21) dönem embriyo ölümleri olarak isimlendirilmiştir.

\section{İstatistik Analizler}

Kontrol ve deneme grubunun yumurta ağırlığı, yumurta kabuk kalınlığı ve kabuk k1rilma direncine ait verileri $\mathrm{T}$ Testi kullanılarak karşılaştırılmıştır. Kırık ve dölsüz yumurta oranları ile çıkım, sskarta civciv ve embriyo ölüm oranlarının karşılaştırılmalarında ise Ki-kare testi kullanılmıştır. Önemlilik düzeyi olarak $P<0.05$ seçilmiştir.

Verilerin değerlendirilmesinde SPSS 13 (SPSS 13. 2004) istatistik programından yararlanılmıştır ${ }^{15}$.

\section{Bulgular}

Kontrol ve deneme grubuna ait yumurta ağırlığı ve yumurta kabuk kalitesine ilişkin parametreler (kırık yumurta oran1, yumurta kabuk kalınlığı, kabuk kırılma direnci) Tablo 2'de, kuluçka sonuçlarına ilişkin değerler (dölsüz yumurta, çıkım, 1skarta civciv ve embriyo ölüm oranları) ise Tablo 3 'te gösterilmiştir.

Tablo 2 incelendiğinde; araştırmanın başlangici olan 38. hafta ile 40, 42, 44 ve 48 . haftalarda yapılan ölçümlerde, kontrol ve deneme grubunun yumurta ağırlıkları ile kırık yumurta oranları arasında önemli bir farklılığın bulunmadığ 1 görülmektedir. Aynı tablo incelendiğinde; $1.25(\mathrm{OH})_{2} \mathrm{D}_{3}$ katk1lı rasyonu tüketen deneme grubunun yumurta kabuk kalınlığında 40
$(\mathrm{P}<0.05)$ ve 48. $(\mathrm{P}<0.01)$ haftalarda, yumurta kabuk kırılma direncinde ise 42. haftada $(\mathrm{P}<0.05)$ istatistik düzeyde bir iyileşmenin olduğu anlaşılmaktadır. Ancak araştırma süresince yapılan ölçümler total olarak değerlendirildiğinde (38-48. haftalar), $1.25(\mathrm{OH})_{2} \mathrm{D}_{3}$ 'ün kabuk kalitesine ilişkin parametreler üzerinde herhangi bir etkiye yol açmadığı dikkati çekmektedir (Tablo 2). Yine kuluçka sonuçlarına ilişsin değerlerin verildiği Tablo 3 incelendiğinde de kontrol ve deneme grubunun dölsüz yumurta, çıkım, 1skarta civciv, erken, orta ve geç dönem embriyo ölüm oranları arasında oluşan farklılıkların istatistik açıdan önem taşımadığı görülmektedir.

Tablo 1. Araştırmada kullanılan damızlık yumurtaci tavuk rasyonunun ham madde bileşimi ve besin madde içeriği (doğal halde).

Table 1. Nutrient ingredients and chemical composition of the experimental layer breeder diets (as fed basis).

\begin{tabular}{|lc|}
\hline \multicolumn{1}{|c|}{ Ham Maddeler (\%) } & $\begin{array}{c}\text { Damızlık Yumurtacı Tavuk } \\
\text { Yemi }\end{array}$ \\
\hline Mısır & 42.25 \\
Soya Küspesi \%48 & 24.40 \\
Buğday & 20.00 \\
Ayçiçeği Küspesi \%28 & 1.08 \\
Bitkisel Yağ & 1.15 \\
Mermer Tozu & 8.89 \\
MDCP \%22 & 1.38 \\
Tuz & 0.27 \\
Vitamin Premiksi1 & 0.25 \\
Mineral Premiksi & 0.10 \\
Sodyumbikarbonat & 0.10 \\
Kolin Klorid \%70 & 0.08 \\
DL- Metiyonin & 0.05 \\
TOPLAM & 100 \\
\hline Kimyasal Bileşim & \\
Kuru madde, \% & 88.26 \\
Ham protein, \% & 17.45 \\
Ham yağ, \% & 3.24 \\
Ham kül, \% & 11.36 \\
Ham selüloz, \% & 2.94 \\
Kalsiyum, \% & 3.73 \\
Toplam fosfor, \% & 0.66 \\
Lizin, \% & 0.87 \\
Metiyonin+Sistin, \% & 0.75 \\
Metabolik enerji, (kcal/kg) & 2721 \\
\hline
\end{tabular}

${ }^{1}$ Yemin her kg'ına 15000 IU Vitamin A, 2500 IU Vitamin $\mathrm{D}_{3}, 100 \mathrm{mg}$ Vitamin E, $4.5 \mathrm{mg}$ Vitamin $\mathrm{K}_{3}, 3.5 \mathrm{mg}$ Vita$\min \mathrm{B}_{1}, 10 \mathrm{mg}$ Vitamin $\mathrm{B}_{2}, 6 \mathrm{mg}$ Vitamin $\mathrm{B}_{6}, 0.02 \mathrm{mg}$ Vitamin $B_{12}, 2$ mg Folik asit, 2 mg D-Biotin, $30 \mathrm{mg}$ Nikotik asit, 20mg Pantotenik asit, $100 \mathrm{mg}$ Vitamin C ilave edilmiştir.

${ }^{2}$ Yemin her kg'ına $100 \mathrm{mg}$ Manganez, 25 mg Demir, 60 $\mathrm{mg}$ Çinko, $10 \mathrm{mg}$ Bakır, $0.2 \mathrm{mg}$ Selenyum, $0.5 \mathrm{mg}$ İyot, $100 \mathrm{mg}$ Kobalt, $200 \mathrm{mg}$ Antioksidan ilave edilmiştir. 
Tablo 2: Bitkisel kaynaklı 1.25-dihidroksikolekalsiferol'ün yumurta ağırlığı, kırik yumurta oranı, yumurta kabuk kalınlığı ve kabuk kırılma direnci üzerine etkisi.

Table 2: Effect of herbal 1.25-dihydroxycholecalciferol on egg weight, cracked egg ratio, eggshell thickness and eggshell breaking strength.

\begin{tabular}{|c|c|c|c|}
\hline & \multicolumn{2}{|c|}{ GRUPLAR } & \multirow[t]{2}{*}{$P$} \\
\hline & $\begin{array}{c}\text { Kontrol } \\
\bar{x} \pm s \bar{x}\end{array}$ & $\begin{array}{l}\text { Deneme } \\
\bar{x} \pm \varsigma \bar{x}\end{array}$ & \\
\hline \multicolumn{4}{|l|}{ Yumurta Ağırlığı (g) } \\
\hline Başlangıç (38. Hafta) & $59.20 \pm 0.38$ & $59.98 \pm 0.36$ & ÖD \\
\hline 1. Ölçüm (40. Hafta) & $60.21 \pm 0.35$ & $60.64 \pm 0.39$ & ÖD \\
\hline 2. Ölçüm (42. Hafta) & $59.53 \pm 0.37$ & $59.59 \pm 0.38$ & ÖD \\
\hline 3. Ölçüm (44. Hafta) & $59.79 \pm 0.39$ & $59.72 \pm 0.38$ & ÖD \\
\hline 4. Ölçüm (48. Hafta) & $58.10 \pm 0.33$ & $59.23 \pm 0.35$ & ÖD \\
\hline GENEL & $59.36 \pm 0.17$ & $59.63 \pm 0.17$ & ÖD \\
\hline \multicolumn{4}{|c|}{ Yumurta Kabuk Kırılma Direnci (N) } \\
\hline Başlangıç (38. Hafta) & $45.09 \pm 0.53$ & $45.67 \pm 0.45$ & ÖD \\
\hline 1. Ölçüm (40. Hafta) & $45.58 \pm 0.40$ & $46.36 \pm 0.54$ & ÖD \\
\hline 2. Ölçüm (42. Hafta) & $44.72 \pm 0.49$ & $46.45 \pm 0.53$ & $(P<0.05)$ \\
\hline 3. Ölçüm (44. Hafta) & $44.83 \pm 0.52$ & $44.88 \pm 0.49$ & ÖD \\
\hline 4. Ölçüm (48. Hafta) & $43.78 \pm 0.51$ & $44.52 \pm 0.50$ & ÖD \\
\hline GENEL & $45.00 \pm 0.22$ & $45.57 \pm 0.23$ & ÖD \\
\hline \multicolumn{4}{|c|}{ Yumurta Kabuk Kalınlığı (mm) } \\
\hline Başlangıç (38. Hafta) & $0.42 \pm 0.01$ & $0.42 \pm 0.01$ & ÖD \\
\hline 1. Ölçüm (40. Hafta) & $0.42 \pm 0.01$ & $0.43 \pm 0.01$ & $(P<0.05)$ \\
\hline 2. Ölçüm (42. Hafta) & $0.42 \pm 0.01$ & $0.42 \pm 0.01$ & ÖD \\
\hline 3. Ölçüm (44. Hafta) & $0.42 \pm 0.01$ & $0.41 \pm 0.01$ & ÖD \\
\hline 4. Ölçüm (48. Hafta) & $0.41 \pm 0.01$ & $0.40 \pm 0.01$ & $(P<0.01)$ \\
\hline GENEL & $0.42 \pm 0.01$ & $0.42 \pm 0.01$ & ÖD \\
\hline Kırık Yumurta Oranı (\%) & $0.93 \pm 0.02$ & $0.89 \pm 0.02$ & ÖD \\
\hline
\end{tabular}

ÖD: Önemli değil.

Tablo 3: Bitkisel kaynaklı 1.25-dihidroksikolekalsiferol'ün kuluçka sonuçlarına etkisi.

Table 3: Effect of herbal 1.25-dihydroxycholecalciferol on hatching results.

\begin{tabular}{|c|c|c|c|}
\hline & \multicolumn{2}{|c|}{ GRUPLAR } & \multirow[t]{2}{*}{$P$} \\
\hline & $\begin{array}{l}\text { Kontrol } \\
\bar{x} \pm S \bar{x}\end{array}$ & $\begin{array}{l}\text { Deneme } \\
\bar{x} \pm \mathrm{s} \bar{x}\end{array}$ & \\
\hline Dölsüz Yumurta Oranı (\%) & $6.59 \pm 0.26$ & $6.48 \pm 0.27$ & ÖD \\
\hline Çıkım Oranı (\%) & $40.95 \pm 0.21$ & $41.07 \pm 0.17$ & ÖD \\
\hline Iskarta Civciv Oranı (\%) & $0.20 \pm 0.02$ & $0.17 \pm 0.02$ & ÖD \\
\hline \multicolumn{4}{|l|}{ Embriyo Ölümü (\%) } \\
\hline Erken Dönem & $5.30 \pm 0.21$ & $5.38 \pm 0.16$ & ÖD \\
\hline Orta Dönem & $0.73 \pm 0.04$ & $0.76 \pm 0.04$ & ÖD \\
\hline Geç Dönem & $5.28 \pm 0.37$ & $5.08 \pm 0.35$ & ÖD \\
\hline
\end{tabular}

ÖD: Önemli değil.

\section{Tartışma ve Sonuç}

Araştırma süresi total olarak değerlendirildiğinde (38-48. haftalar); damızlık yumurtac1 tavuk rasyonlarına Solanum glaucophyllum bitkisinden elde edilen $1.25(\mathrm{OH})_{2} \mathrm{D}_{3}{ }^{\prime}$ 'ün kat1lmas1, yumurta kabuk kalitesine ilişkin parametreler üzerinde herhangi bir etkiye yol açmamıştır. Ancak, $1.25(\mathrm{OH})_{2} \mathrm{D}_{3}$ katkıl1 yemi tüketen deneme grubun yumurta kabuk kalınlığında 40 $(\mathrm{P}<0.05)$ ve 48. $(\mathrm{P}<0.01)$ haftalarda, kabuk k1rilma direncinde ise 42 . haftada $(\mathrm{P}<0.05)$ istatistik düzeyde artış saptanmıştır (Tablo 2). Araştırmanın bazı dönemlerinde; deneme grubunun yumurta kabuk kalınlığ 1 ve kabuk kırılma direncinde gözlenen bu artışın, rasyona ilave edilen $1.25(\mathrm{OH})_{2} \mathrm{D}_{3}$ 'ün $\mathrm{Ca}$ absorsiyonu üzerindeki pozitif etkisinden kaynaklanabileceği düşünülmektedir. Nitekim konuya ilişkin çalışmalarda; Solanum glaucophyllum 'un yapraklarından elde edilen ekstraktların, vitamin D bakımından yetersiz beslenen civciv ve ratlarda Ca'un absorbsiyonunu önemli düzeyde artırdığı tespit edilmiştir ${ }^{14,16}$. Bar ve Hurwitz'; $1.25(\mathrm{OH})_{2} \mathrm{D}_{3}$ 'ün bağırsak epitelyumunda $\mathrm{Ca}$ 'u bağlayan proteinlerin sentezini uyararak, Ca'un absorbsiyonunu ve uterusa transfer olmasını sağlamak suretiyle yumurta kabuğunun şekillenmesinde önemli bir rol oynadığını bildirmiştir. Damızlık yumurtacı tavuk rasyonlarına katılan $1.25(\mathrm{OH})_{2} \mathrm{D}_{3}$ 'ün yumurta kabuk kalitesi üzerindeki total etkisinin istatistik açıdan önem taşımaması, bu araștırmada kullanılan tavukların genç yaşta olmasına bağlanmıştır. Nitekim yumurtlama devresine yeni giren tavuklarda oldukça yüksek olan yumurta kabuk kalitesinin, yumurtlama devresinin ileriki aşamalarında $\mathrm{Ca}$ ve vitamin $\mathrm{D}_{3}$ metabolizmasındaki yetersizliklere bağlı olarak giderek azaldığ 1 ve bu durumun ince kabuklu yumurtaların oranında artışa yol açtığ bildirilmektedir $^{2}$. Joyner ve ark. $^{7}$ ise ince kabuklu yumurtaların oranındaki artıştan, tavuğun yaşı arttıkça yumurta büyüklügünde meydana gelen artışın sorumlu olabileceğini ileri sürmüşlerdir.

Damızlık olarak yetiştirilen kanatlı hayvanlarda kemik bütünlügü ve yüksek yumurta verimini sürdürmenin yanı sıra kuluçka sonuçlarını direkt olarak etkilemesinden dolayı üretilen yumurtaların yüksek kabuk kalitesine sahip olması istenmektedir. Araştırmamızda kontrol ve deneme grubunun kuluçka sonuçlarına ilişkin parametreleri arasında da önemli bir farklılık saptanmamıştır (Tablo 3). Kontrol ve deneme grubundaki hayvanların yumurta kabuk kalitesinde önemli bir farklılı̆gın bulunmaması bu 
sonuca yol açmış olabilir. Hunton'un ${ }^{6}$; yumurta kabuğunun embriyoyu diş etkilerden ve enfeksiyonlardan koruyarak, yumurtadan su kayıplarını önleyerek, ayrıca iskelet gelişimi için embriyoya gerekli Ca'u sağlayarak kuluçka sonuçlarını önemli düzeyde etkilediği yönündeki bildirişi bu görüşü destekler niteliktedir.

Sonuç olarak damızlık yumurtacı tavuk rasyonlarına Solanum glaucophyllum kaynaklı $1.25(\mathrm{OH})_{2} \mathrm{D}_{3}$ katılması; araştırmanın bazı dönemlerinde yumurta kabuk kalitesinde iyileşmeye yol açarken, araştırma süresi total olarak değerlendirildiğinde aynı etkiyi gösterememiştir. $\mathrm{Bu}$ durumun araştırmada kullanılan tavukların genç yaşta olmasından kaynaklanabileceği düşünülmektedir. Damızlık yumurtacı tavuk rasyonlarına katılan $1.25(\mathrm{OH})_{2} \mathrm{D}_{3}$ 'ün, yumurta kabuk kalitesinin yanı sıra kuluçka sonuçları üzerinde de önemli bir etkisi saptanmamıştır. Yumurta kabuk kalitesinin kuluçka sonuçlarına etkisi göz önüne alındığında; araştırmamızda kabuk kalitesinde saptanan bu durumun, kuluçka sonuçlarına yansıdığ 1 düşünülmektedir. $\mathrm{Bu}$ araștırmada kullanılan damızlık yumurtacı tavukların yaşı dikkate alındığında; Vitamin D'nin aktif formu olan $1.25(\mathrm{OH})_{2} \mathrm{D}_{3}{ }^{\prime}$ ün, vitamin D metabolizmasında aksaklıkların yaşandığı yaşlı hayvanların rasyonlarına katılması durumunda etkili olabileceği kanısına varılmıştır.

\section{Kaynaklar}

1. Balnave, D., Muheereza, S.K., 1997. Improving eggshell quality at high temperatures with dietary sodium bicarbonate. Poult. Sci., 76, 588-593.

2. Bar, A., Hurwitz, S., 1987. Vitamin D metabolism and calbindin (calcium binding protein) in aged laying hens. J. Nutr., 117, 1775-1779.

3. Boland, R. L., Skliar, M. I., Norman, A. W., 1987. Isolation of vitamin $D_{3}$ metabolites from Solanum malacoxylon leaf extracts incubated with ruminal fluid. Planta Med., 53, 161-164.

4. Combs, G. F. Jr., 1998. Vitamin D. The Vitamins: Fundamental Aspects in Nutrition and Health. $2^{\text {nd }}$ Ed., San Diego, California, pp. 156-186.
5. DeLuca H.F., 1988. The vitamin D story: A collaborative of basic science and clinical medicine. FASEB J., 2, 224-236.

6. Hunton, P., 2005. Research on eggshell structure and quality: An historical overview. Braz. J. Poult. Sci., 2, 67-71.

7. Joyner, C.J., Peddie, M.J., Taylor, T.G., 1987. The effect of age on egg production in the domestic hen. Gen. Comp. Endocr., 65, 331-336.

8. Moran, E. T. Jr., 2007. Nutrition of the developing embryo and hatchling. Poult. Sci., 86, 10431049.

9. Narbaitz, R., Tsang, C. P. W., 1989. Vitamin D deficiency in the chick embryo: The effects of prehatching motility and on the growth and differentiation of bones, muscles and parathyroid glands. Calcif. Tiss. Int., 44, 348-355.

10. Narbaitz, R., Tsang, C. P. W., Grunder, A., 1987. The effects of vitamin D deficiency in the chick embryo. Calcif. Tiss. Int., 40, 109-113.

11. Norman, A.W., Roth, J., Orci, L., 1982. The vitamin D endocrine system: steroid metabolism, hormone receptors, and biological response (calcium binding proteins). Endoc. Rev., 3, 331-366.

12. Roberts J.R., Nolan J.V., 1997. Egg and eggshell quality in five strains of laying hen and the effect of calcium source and age. In: Kijowski, J., Pikul, J. (Eds.), Eggs and Egg Products Quality. pp. 3844. Proceedings of The VII European Symposium on The Quality of Eggs and Egg Products, 21-26 September, Poznan, Poland.

13. Roque, L., Soares, M.C., 1994. Effects of egg shell quality and broiler breeders age on hatchability. Poult. Sci., 73, 1835-1845.

14. Schneider, L.E., Schedl, H.P., 1977. Effects of Solanum malacoxylon on duodenal calcium binding protein in the diabetic rat. Endocrinology, 100, 928-933.

15. SPSS. 1999. SPSS for Windows, SPSS 13. 2004. SPSS INC.. Chicago. IL. USA.

16. Wasserman, R.H., Henion, J.D., Haussler, M.R., McCain, T.A., 1976. Calcinogenic factor in Solanum malacoxylon: Evidence that it is 1.25dihydroxyvitamin $\mathrm{D}_{3}$-glycoside. Science, 194, 853-855.

17. Wilson, H. R., 1997. Effects of maternal nutrition on hatchability. Poult. Sci., 76, 134-143. 
